\title{
Prevalence of iron deficiency states and risk of haemoconcentration during pregnancy according to initial iron stores and iron supplementation
}

\author{
Victoria Arija ${ }^{1,2}$, Blanca Ribot ${ }^{1}$ and Núria Aranda ${ }^{1, *}$ \\ 'Unitat de Nutrició i Salut Pública, Research Group in Nutrition and Mental Health (NUTRISAM), Institut \\ d'Investigació Sanitària Pere Virgili (IISPV), Universitat Rovira i Virgili, C/Sant Llorenç 21, 43201 Reus, Spain: \\ ${ }^{2}$ Institut d'Investigació en Atenció Primària, Jordi Gol i Gurina, Catalunya, Spain
}

Submitted 22 February 2012: Final revision received 30 January 2013: Accepted 5 February 2013: First published online 11 March 2013

\begin{abstract}
Objective: To describe the prevalence of iron depletion (ID), iron-deficiency anaemia (IDA) and risk of haemoconcentration during pregnancy and at delivery and to assess the influence of initial Fe stores and Fe supplementation on that prevalence.

Design: Longitudinal study.

Setting: Hospital Universitari Sant Joan de Reus (Catalonia, Spain).

Subjects: Two hundred and eighty-five pregnant women. Serum ferritin and $\mathrm{Hb}$ were measured in the first, second and third trimesters and at delivery. Women were classified according to initial Fe stores as ID or no ID (serum ferritin $\geq 12 \mu \mathrm{g} / \mathrm{l}$ ) and according to Fe supplement use as supplemented or nonsupplemented.

Results: Initial ID was $16 \cdot 2 \%$. At delivery, $45 \cdot 7 \%$ had ID, $13 \cdot 5 \%$ IDA and $13 \cdot 3 \%$ had risk of haemoconcentration. Initial ID and non-supplemented groups had significantly higher prevalences of ID and IDA and lower risk of haemoconcentration at delivery than the other groups. In the multiple logistic models, no initial ID and Fe supplementation exerted a protective effect against ID at delivery (adjusted $\mathrm{OR}=0 \cdot 28 ; 95 \%$ CI $0 \cdot 13,0.58$ and adjusted $\mathrm{OR}=0 \cdot 39 ; 95 \%$ CI $0 \cdot 22,0 \cdot 69$, respectively). Moderate Fe supplementation did not seem to clearly prevent IDA (adjusted OR $=0.91 ; 95 \%$ CI $0 \cdot 42,1 \cdot 96$ ) or to enhance the haemoconcentration (adjusted OR $=1 \cdot 42 ; 95 \%$ CI $0 \cdot 58,3 \cdot 50$ ).

Conclusions: The prevalence of ID and IDA was high in late pregnancy in healthy pregnant women, particularly in those with initial ID and/or those not taking supplements. Starting pregnancy with no ID and/or taking moderate Fe supplementation decreased the likelihood of ID at delivery. The risk of haemoconcentration was high at delivery, but did not seem to be promoted by Fe supplementation. Further research is necessary to determine the most appropriate nutritional advice for pregnant women.
\end{abstract}

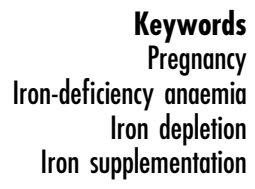

Keywords

anaemio

Iron depletion

Iron supplementation
Pregnant women are at special risk of Fe deficiency because Fe requirements increase during pregnancy and are difficult to cover by diet alone ${ }^{(1)}$. In addition, a significant percentage - between 11 and 36\% - of European women of childbearing age already have depleted Fe stores even before becoming pregnant ${ }^{(2)}$. As a result of this negative $\mathrm{Fe}$ balance, the prevalence of anaemia during pregnancy is about $25 \%$ in Europe ${ }^{(3)}$.

Although the prevalence of anaemia has been extensively evaluated in pregnant women in different countries, the WHO reports that data on the prevalence of Fe deficiency are scarce despite being considered the primary cause of anaemia $^{(3)}$. Furthermore, there are also few data on the prevalence of risk of haemoconcentration, defined as
$\mathrm{Hb}>130 \mathrm{~g} / \mathrm{l}$ by a recent Cochrane meta-analysis ${ }^{(4)}$, which may be produced by excessive Fe supplementation.

However, both Fe deficiency and haemoconcentration during pregnancy are associated with adverse effects on the health of the mother and fetus ${ }^{(4-6)}$.

Recently, some authors have described the importance of Fe stores in early pregnancy, suggesting that although high Fe stores might prevent Fe deficiency at the end of gestation $^{(7,8)}$, the risk of haemoconcentration might increase if pregnant women take Fe supplements ${ }^{(9)}$. On the other hand, other authors suggest that there is no relationship between Fe supplementation and this risk ${ }^{(6,10)}$ and that women who are supplemented with Fe during pregnancy might present Fe deficiency less often than women who are not. 
Therefore, the present study aimed to assess the prevalence of Fe depletion, Fe-deficiency anaemia and risk of haemoconcentration in pregnant women in an industrialized country during each trimester of pregnancy and at delivery, and to describe the prevalence in relation to initial Fe stores of the mother and Fe supplementation.

\section{Materials and methods}

A longitudinal study was carried out with pregnant women through to delivery. Pregnant women were recruited at the Unit of Obstetrics and Gynaecology at the reference clinical centre of Hospital Universitari Sant Joan de Reus (Catalonia, Spain) during their first prenatal care appointment (gestational week 10). The volunteers admitted to the study signed an informed consent, according to the Declaration of Helsinki. The Sant Joan's Hospital ethics committee approved the study.

Inclusion criteria were as follows: Caucasian; over 18 years of age; and recruited between weeks 8 and 12 of gestation. Exclusion criteria were: the presence of any chronic illness or a possible inflammation diagnosed when high serum ferritin (SF) levels (SF $>62 \mu \mathrm{g} / \mathrm{l})^{(11)}$ and low transferrin saturation (TS $<16 \%$ ) occurred simultaneously; taking a higher Fe supplement dose than recommended by the obstetrician $(>80 \mathrm{mg} / \mathrm{d})$; and having a multiple pregnancy (twins or triplets).

From a total of 300 pregnant women recruited, twelve were excluded for taking Fe supplement doses over $80 \mathrm{mg} / \mathrm{d}$ and three had a possible inflammation that might have altered their biochemical parameters. The final study sample comprised 285 women. Data were collected over four visits and at delivery.

At the first appointment with obstetrics, around the 10th week of gestation, socio-economic status and BMI were recorded, data were collected from the medical history and venous blood was extracted for further laboratory analyses. During the second prenatal appointment, around weeks 13-15 of gestation, the obstetrician recommended Fe supplementation of between 40 and $80 \mathrm{mg} / \mathrm{d}$ to all the women and recorded whether they had taken any previously. At subsequent appointments, during the 24th and 34 th weeks of gestation and at delivery, further blood samples were taken.

At the same time, using a semi-structured questionnaire designed by the researchers, a trained professional (not a member of the regular health-care staff, in order to not influence the responses of the women) recorded the initial and continuing supplementation month by month, as well as the number of days per week that the supplements were usually taken.

\section{Medical record abstraction}

The socio-economic level of the family was assessed using the Hollingshead index ${ }^{(12)}$ and the results were grouped into three categories as 'low', 'medium' or 'high'.
BMI $\left(\mathrm{kg} / \mathrm{m}^{2}\right)$ was calculated as weight in kilograms divided by the square of height in metres. The amount in milligrams of the total Fe supplementation was calculated as:

Total Fe supplementation $(\mathrm{mg})=($ supplement Fe content $\times$ days per week $\times$ number of weeks),

and the daily Fe supplementation in milligrams was calculated as:

Daily Fe supplementation $(\mathrm{mg})=($ total Fe supplementation/number of days between the beginning of the supplementation until delivery).

Infant birth weight was measured with a SECA electronic weighbridge (Vogel \& Halke GmbH \& Co., Hamburg, Germany) within an accuracy of $10 \mathrm{~g}$.

\section{Laboratory analyses}

The assessments of SF, TS and $\mathrm{Hb}$ were used to estimate the different compartments of body $\mathrm{Fe}$ : Fe stores by $\mathrm{SF}$, the circulating level by TS, and the contribution of $\mathrm{Fe}$ to the bone marrow by $\mathrm{Hb}$.

From the blood samples, $\mathrm{Hb}$ values were immediately measured using a Coulter Gen-S analyser (Coulter, Hialeah, FL, USA). Plasma was processed and stored at $-80^{\circ} \mathrm{C}$ at the Institut d'Investigació Sanitària Pere Virgili (IISPV) Biobanc in Reus (www.iispv.cat) until required for analysis. This allowed all of the samples to be analysed together using the same kit, thereby limiting the potential for bias in the values obtained.

SF was determined by turbidimetric immunoassay as described previously ${ }^{(13)}$; serum transferrin and serum $\mathrm{Fe}$ by spectrophotometry (Biokit SA, Barcelona, Spain and ITC Diagnostics SA, Barcelona, Spain) using standard clinical chemistry techniques.

TS was calculated as ${ }^{(14)}$ :

$\operatorname{TS}(\%)=[\operatorname{serum~Fe}(\mu \mathrm{mol} / \mathrm{l}) /$ serum transferrin $(\mathrm{g} / \mathrm{l})] \times 3 \cdot 9$.

\section{Definitions}

'Iron depletion' (ID) was defined as SF $<12 \mu \mathrm{g} / 1$ and 'anaemia' as $\mathrm{Hb}$ values lower than $110 \mathrm{~g} / \mathrm{l}$ in the first or third trimester and at delivery and $\mathrm{Hb}$ values lower than $105 \mathrm{~g} / \mathrm{l}$ in the second trimester ${ }^{(15)}$. 'Iron-deficiency anaemia' (IDA) was defined as anaemia and $\mathrm{SF}<12 \mu \mathrm{g} / 1$ simultaneously, and 'risk of haemoconcentration' as $\mathrm{Hb}$ values higher than $130 \mathrm{~g} / \mathrm{l}$ in the second or third trimester of gestation and at delivery ${ }^{(4)}$.

'Inflammation' was defined as high SF levels ${ }^{(11)}$ and low TS levels (defined as TS $<16 \%$ ).

'Preterm' was defined as babies born before the 37th week of gestation and 'low birth weight' as babies weighing $<2500 \mathrm{~g}$. 
Table 1 General, socio-economic and obstetric characteristics of the participants and their newborns; Reus, Catalonia, Spain ( $n$ 285)

\begin{tabular}{|c|c|c|}
\hline & Mean & SD \\
\hline \multicolumn{3}{|l|}{ Mothers } \\
\hline Age (years) & $31 \cdot 1$ & $4 \cdot 4$ \\
\hline $\mathrm{BMl}$ at the first visit $\left(\mathrm{kg} / \mathrm{m}^{2}\right)$ & $23 \cdot 3$ & $3 \cdot 5$ \\
\hline Smoker (\%) & \multicolumn{2}{|c|}{$19 \cdot 9$} \\
\hline Socio-economic status of the family (\%) & \multirow{2}{*}{\multicolumn{2}{|c|}{9.4}} \\
\hline Low & & \\
\hline Medium & \multicolumn{2}{|c|}{$44 \cdot 8$} \\
\hline High & \multicolumn{2}{|c|}{$45 \cdot 9$} \\
\hline Primipara (\%) & \\
\hline Gestation length (weeks) & $39 \cdot 1$ & $1 \cdot 6$ \\
\hline \multicolumn{3}{|l|}{ Newborns } \\
\hline Gender (\% male) & \multicolumn{2}{|c|}{$50 \cdot 6$} \\
\hline Birth weight $(\mathrm{g})$ & $3217 \cdot 7$ & $439 \cdot 8$ \\
\hline Birth weight adjusted for gender and gestation week (g) & $3201 \cdot 1$ & $250 \cdot 8$ \\
\hline Low birth weight (\%) & \multicolumn{2}{|c|}{$5 \cdot 5$} \\
\hline Preterm (\%) & & \\
\hline
\end{tabular}

Values are presented as means and standard deviations, or as percentages.

Women who took Fe supplements on fewer than $2 \mathrm{~d} /$ week were included in the non-supplemented group.

\section{Statistical analyses}

All statistical analyses were performed with the SPSS statistical software package version $19 \cdot 0$. Categorical data are presented as relative (\%) frequencies. Continuous variables were checked for normality of distribution. All continuous variables were normally distributed, except for the SF values, and are presented as means and standard deviations. SF values were log-transformed and are presented as geometric mean and standard deviation. A Student's $t$ test was used to compare continuous data and the two-proportion $Z$-test was used to compare categorical data. A two-way ANOVA was applied to detect an interaction between ID and Fe supplementation for continuous variables. When the interaction was significant, post hoc pairwise comparisons with $P$ values corrected by the Bonferroni method were performed. The magnitude of the association between no initial ID and daily Fe supplementation with ID, IDA or $\mathrm{Hb}>130 \mathrm{~g} / \mathrm{l}$ at delivery was evaluated using multiple logistic regression analyses. First, we ran three models to assess simultaneously the effect of no initial ID and Fe supplementation (independent variables) on each of the dependent variables: ID, IDA and $\mathrm{Hb}>130 \mathrm{~g} / \mathrm{l}$ at delivery. Subsequently the previous models were adjusted for the age of the mother, parity, tobacco use, gestational age and birth weight. In all cases, the level of significance was set at $P<0 \cdot 05$.

\section{Results}

Table 1 describes the general, obstetric and socioeconomic characteristics of the group of healthy pregnant women who participated in the study, as well as the characteristics of their newborns. Table 2 shows the
Table 2 Prevalence of iron deficiency states and risk of haemoconcentration in pregnant women; Reus, Catalonia, Spain ( $n$ 285)

\begin{tabular}{lr}
\hline Baseline characteristics & \\
\hline Hb 10th week $(\mathrm{g} / \mathrm{l})$ & \\
Mean & $125 \cdot 7$ \\
SD & $8 \cdot 2$ \\
SF 10th week $(\mu \mathrm{g} / \mathrm{l})^{*}$ & $27 \cdot 9$ \\
Mean & $2 \cdot 3$ \\
SD & \\
ID (\%) & $16 \cdot 2^{\mathrm{a}}$ \\
1st trimester & $52 \cdot 3^{\mathrm{b}}$ \\
2nd trimester & $66 \cdot 1^{\mathrm{c}}$ \\
3rd trimester & $45 \cdot 7^{\mathrm{d}}$ \\
Delivery & \\
Anaemia $(\%)$ & $3 \cdot 2^{\mathrm{a}}$ \\
1st trimester $(\mathrm{Hb}<110 \mathrm{~g} / \mathrm{l})$ & $12 \cdot 9^{\mathrm{b}}$ \\
2nd trimester $(\mathrm{Hb}<105 \mathrm{~g} / \mathrm{l})$ & $27 \cdot 5^{\mathrm{c}}$ \\
3rd trimester $(\mathrm{Hb}<110 \mathrm{~g} / \mathrm{l})$ & $18 \cdot 8^{\mathrm{d}}$ \\
Delivery $(\mathrm{Hb}<110 \mathrm{~g} / \mathrm{l})$ & \\
IDA (\%) & $1 \cdot 0^{\mathrm{a}}$ \\
1st trimester & $9 \cdot 6^{\mathrm{b}}$ \\
2nd trimester & $21 \cdot 5^{\mathrm{c}}$ \\
3rd trimester & $13 \cdot 5^{\mathrm{d}}$ \\
Delivery & \\
Hb $>130 \mathrm{~g} / \mathrm{l}(\%)$ & $1 \cdot 9^{\mathrm{a}}$ \\
2nd trimester & $4 \cdot 2^{\mathrm{b}}$ \\
3rd trimester & $13 \cdot 3^{\mathrm{c}}$ \\
Delivery & \\
\hline
\end{tabular}

SF, serum ferritin; ID, iron depletion; IDA, iron-deficiency anaemia. ID was defined as SF $<12 \mu \mathrm{g} / \mathrm{l}$; IDA was defined as anaemia and ID simultaneously; risk of haemoconcentration was defined as $\mathrm{Hb}>130 \mathrm{~g} / \mathrm{l}$. Values are presented as means and standard deviations, or as percentages. $a, b, c, d$ Proportions within a column with unlike superscript letters were significantly different $(P<0 \cdot 05)$.

${ }^{*}$ Geometric mean (antilog SD).

prevalence of Fe deficiency states and of risk of haemoconcentration by trimester of gestation in the women. The prevalence of all Fe deficiency states measured in the study increased as pregnancy progressed and decreased at delivery, when haemodilution reduces, except in the case of haemoconcentration, which continued to increase until delivery. 
Table 3 Prevalence of iron deficiency states and risk of haemoconcentration as a function of initial iron stores and iron supplementation in pregnant women; Reus, Catalonia, Spain ( $n$ 285)

\begin{tabular}{|c|c|c|c|c|c|c|c|c|c|c|c|}
\hline & \multicolumn{5}{|c|}{ Initial Fe stores } & \multicolumn{5}{|c|}{ Fe supplementation } & \multirow{3}{*}{$\begin{array}{c}P \text { for } \\
\text { interaction }\end{array}$} \\
\hline & \multicolumn{2}{|c|}{ No ID (n 237) } & \multicolumn{2}{|c|}{ ID (n 48) } & \multirow[b]{2}{*}{$P$ value } & \multicolumn{2}{|c|}{ Yes $(n 209)$} & \multicolumn{2}{|c|}{ No $(n 76)$} & \multirow[b]{2}{*}{$P$ value } & \\
\hline & Mean & SD & Mean & SD & & Mean & SD & Mean & SD & & \\
\hline \multicolumn{12}{|l|}{ General characteristics } \\
\hline $\mathrm{Hb}$ 10th week $(\mathrm{g} / \mathrm{l})$ & $126 \cdot 5$ & $7 \cdot 7$ & $123 \cdot 5$ & $9 \cdot 2$ & 0.016 & $125 \cdot 1$ & $8 \cdot 1$ & $127 \cdot 6$ & $8 \cdot 2$ & 0.015 & 0.224 \\
\hline SF 10 th week $\left(\mu \mathrm{g} / \mathrm{l}^{\star}\right.$ & $36 \cdot 3$ & $1 \cdot 8$ & $7 \cdot 1$ & $1 \cdot 6$ & $<0.001$ & $27 \cdot 3$ & $2 \cdot 3$ & $28 \cdot 1$ & $2 \cdot 3$ & $0 \cdot 809$ & 0.667 \\
\hline Starting week of supplementation & $14 \cdot 3$ & $9 \cdot 9$ & $13 \cdot 5$ & $9 \cdot 3$ & 0.588 & $18 \cdot 3$ & $7 \cdot 2$ & - & - & $<0.001$ & $0 \cdot 110$ \\
\hline Daily Fe supplementation $(\mathrm{mg})$ & $44 \cdot 2$ & $34 \cdot 4$ & $36 \cdot 7$ & $30 \cdot 3$ & $0 \cdot 158$ & $57 \cdot 8$ & $27 \cdot 7$ & - & - & $<0.001$ & 0.245 \\
\hline Total Fe supplementation (mg) & 6321 & 5088 & 5543 & 4710 & $0 \cdot 323$ & 8367 & 4313 & - & - & $<0.001$ & $0 \cdot 340$ \\
\hline \multirow[t]{2}{*}{ Infant birth weight $(\mathrm{g})$} & 3237 & $441 \cdot 3$ & 3132 & $387 \cdot 3$ & $0 \cdot 130$ & 3231 & $431 \cdot 4$ & 3179 & $462 \cdot 5$ & 0.348 & $0 \cdot 361$ \\
\hline & \multicolumn{2}{|c|}{$\%$} & \multicolumn{2}{|c|}{$\%$} & & \multicolumn{2}{|c|}{$\%$} & \multicolumn{2}{|c|}{$\%$} & & \\
\hline \multicolumn{12}{|l|}{ ID (\%) } \\
\hline 1st trimester & \multirow{2}{*}{\multicolumn{2}{|c|}{$\begin{array}{r}0 \cdot 0^{\mathrm{a}} \\
46 \cdot 4^{\mathrm{b}}\end{array}$}} & \multicolumn{2}{|c|}{$100 \cdot 0^{\mathrm{a}}$} & $<0.001$ & \multicolumn{2}{|c|}{$14 \cdot 9^{a}$} & \multicolumn{2}{|c|}{$19 \cdot 8^{a}$} & $0 \cdot 380$ & \\
\hline 2nd trimester & & & \multirow{2}{*}{\multicolumn{2}{|c|}{$\begin{array}{l}83 \cdot 3^{\mathrm{b}} \\
81 \cdot 3^{\mathrm{b}, \mathrm{c}}\end{array}$}} & $<0.001$ & \multirow{2}{*}{\multicolumn{2}{|c|}{$50 \cdot 0^{\mathrm{b}}$}} & \multirow{2}{*}{\multicolumn{2}{|c|}{$\begin{array}{l}58 \cdot 8^{b} \\
77 \cdot 5^{c}\end{array}$}} & $0 \cdot 267$ & 0.326 \\
\hline 3rd trimester & \multicolumn{2}{|c|}{$63 \cdot 9^{c}$} & & & 0.019 & & & & & 0.026 & 0.231 \\
\hline Delivery & \multicolumn{2}{|c|}{$40 \cdot 9^{b}$} & \multicolumn{2}{|c|}{$70 \cdot 8^{\mathrm{c}}$} & & \multicolumn{2}{|c|}{$40 \cdot 2^{d}$} & \multicolumn{2}{|c|}{$61 \cdot 3^{\mathrm{b}}$} & & 0.058 \\
\hline Anaemia (\%) & & & & & & & & & & & \\
\hline 1st trimester $(\mathrm{Hb}<110 \mathrm{~g} / \mathrm{l})$ & & $0^{\mathrm{a}}$ & & $\cdot 3^{a}$ & $0 \cdot 123$ & & $5^{a}$ & & $4^{a}$ & $0 \cdot 910$ & 0.799 \\
\hline 2nd trimester $(\mathrm{Hb}<105 \mathrm{~g} / \mathrm{l})$ & & & & $\cdot 8^{\mathrm{b}}$ & 0.087 & 13 & & 11 & & 0.962 & 0.977 \\
\hline 3rd trimester $(\mathrm{Hb}<110 \mathrm{~g} / \mathrm{l})$ & & & & $6^{\mathrm{c}}$ & 0.052 & 27 & & 28 & & 0.789 & $0 \cdot 850$ \\
\hline Delivery $(\mathrm{Hb}<110 \mathrm{~g} / \mathrm{l})$ & & & & $3^{\mathrm{b}, \mathrm{c}}$ & 0.017 & 16 & & 24 & & $0 \cdot 176$ & 0.907 \\
\hline IDA (\%) & & & & & & & & & & & \\
\hline 1st trimester & & $0^{\mathrm{a}}$ & & $3^{a}$ & 0.004 & & $9^{a}$ & & $2^{a}$ & 0.697 & 1 \\
\hline 2nd trimester & & $9^{b}$ & & $\cdot 8^{b}$ & 0.015 & & $6^{\mathrm{b}}$ & & $5^{b}$ & 0.839 & 0.957 \\
\hline 3rd trimester & & & & $\cdot 4^{c}$ & 0.022 & 19 & & 27 & $4^{c}$ & $0 \cdot 141$ & $0 \cdot 708$ \\
\hline Delivery & & & & $\cdot 0^{\mathrm{b}}$ & 0.017 & 12 & & $\begin{array}{l}21 \\
15\end{array}$ & $5^{c}$ & 0.613 & 0.326 \\
\hline $\mathrm{Hb}>130 \mathrm{~g} / \mathrm{l}(\%)$ & & & & & & & & & & & \\
\hline 2nd trimester & & $6^{a}$ & & $\cdot 2^{a}$ & $0 \cdot 252$ & & $8^{a}$ & & $4^{\mathrm{a}, \mathrm{b}}$ & 0.931 & 0.640 \\
\hline 3rd trimester & & $8^{b}$ & & $\cdot 1^{a}$ & $0 \cdot 701$ & & $3^{\mathrm{b}}$ & & $2^{a}$ & $0 \cdot 210$ & 0.997 \\
\hline Delivery & & & & $\cdot 1^{a}$ & 0.010 & 15 & & & $4^{b}$ & $0 \cdot 198$ & 0.990 \\
\hline
\end{tabular}

SF, serum ferritin; ID, iron depletion; IDA, iron-deficiency anaemia.

ID was defined as SF $<12 \mu \mathrm{g} /$; IDA was defined as anaemia and ID simultaneously; risk of haemoconcentration was defined as $\mathrm{Hb}>130 \mathrm{~g} / \mathrm{l}$.

Values are presented as means and standard deviations, or as percentages.

${ }_{a, b, c, d}$ Proportions within a column with unlike superscript letters were significantly different $(P<0 \cdot 05)$.

${ }^{*}$ Geometric mean (antilog SD).

Table 3 shows the baseline characteristics of the participants according to their initial Fe stores and whether or not they took Fe supplements. It also shows the prevalence of ID, IDA and risk of haemoconcentration by trimester of gestation and at delivery.

After checking if there was any interaction between initial ID and Fe supplementation, we observed only a slight interaction regarding the prevalence of ID at delivery $(P=0 \cdot 058)$. It appeared that women with no initial ID who were taking Fe supplements presented a significantly lower prevalence of ID at delivery than women with initial ID who were taking supplements or women with no initial ID who were not taking supplements $(34 \cdot 0 \% v \cdot 72 \cdot 7 \%$ and $60 \cdot 9 \%$, respectively). Except in the case previously mentioned, we present the main effects of ID and Fe supplementation.

Regarding initial Fe stores of the pregnant women, it was shown that a greater number of women with no initial ID did not have anaemia or IDA at delivery compared with women initially with ID, although they were more likely to be at risk of haemoconcentration.

From the group with no ID, seventy-six women (30.0\%) had initial $\mathrm{Hb}$ higher than $130 \mathrm{~g} / \mathrm{l}$. Women with
$\mathrm{Hb}>130 \mathrm{~g} / \mathrm{l}$ at early pregnancy who took Fe supplements had a significantly higher prevalence of risk of haemoconcentration at delivery than women who were not supplemented with Fe $(30 \cdot 0 \% v \cdot 7 \cdot 7 \% ; P=0 \cdot 027)$.

During pregnancy, $78.6 \%$ ( $n$ 224) took Fe supplements. Among them, $6 \cdot 7 \%$ took the supplements on $1-2 \mathrm{~d} /$ week and were therefore classified as non-supplemented ( $n$ 15); $16 \cdot 1 \%$ took them on $5 \mathrm{~d} /$ week and the remaining $77 \cdot 5 \%$ took them on 6-7 d/week.

Women who took Fe supplements had a significantly lower prevalence of ID at delivery than women who did not $(40 \cdot 2 \% v \cdot 61 \cdot 3 \%, P=0 \cdot 003)$, but had a higher prevalence of risk of haemoconcentration, although not statistically significant $(15 \cdot 6 \% v \cdot 8 \cdot 4 \%, P=0 \cdot 198)$.

Table 4 describes the risk of ID, IDA and $\mathrm{Hb}>130 \mathrm{~g} / \mathrm{l}$ at delivery as a function of the initial Fe stores and Fe supplementation. We can appreciate that no ID in the first trimester and Fe supplementation protected against ID at delivery even after adjusting for other variables. Regarding the risk of IDA at delivery, no ID in the first trimester exerted a protective effect, although this relationship was not significant when adjusted for other variables. On the other hand, the risk of haemoconcentration at 
Table 4 Risk of iron deficiency states and haemoconcentration at delivery as a function of initial iron depletion and iron supplementation in pregnant women; Reus, Catalonia, Spain ( $n$ 285)

\begin{tabular}{|c|c|c|c|c|c|c|c|c|c|}
\hline & \multicolumn{3}{|c|}{ ID at delivery } & \multicolumn{3}{|c|}{ IDA at delivery } & \multicolumn{3}{|c|}{$\mathrm{Hb}>130 \mathrm{~g} / \mathrm{l}$ at delivery } \\
\hline & OR & $95 \% \mathrm{Cl}$ & $P$ & OR & $95 \% \mathrm{Cl}$ & $P$ & OR & $95 \% \mathrm{Cl}$ & $P$ \\
\hline \multicolumn{10}{|l|}{ Model 1} \\
\hline \multicolumn{10}{|l|}{ Initial ID } \\
\hline Yes & $1 \cdot 00$ & Ref. & & $1 \cdot 00$ & Ref. & & $1 \cdot 00$ & Ref. & \\
\hline No & $0 \cdot 28$ & $0.14,0.57$ & $<0.001$ & $0 \cdot 41$ & $0 \cdot 19,0 \cdot 88$ & 0.019 & $8 \cdot 85$ & $1 \cdot 18,66 \cdot 1$ & 0.034 \\
\hline \multicolumn{10}{|l|}{ Fe supplementation } \\
\hline No & $1 \cdot 00$ & Ref. & & $1 \cdot 00$ & Ref. & & $1 \cdot 00$ & Ref. & \\
\hline Yes & 0.41 & $0 \cdot 24,0 \cdot 70$ & 0.001 & $0 \cdot 80$ & $0.39,1.64$ & 0.536 & $2 \cdot 98$ & $1 \cdot 05,8 \cdot 99$ & 0.040 \\
\hline \multicolumn{10}{|l|}{ Model 2} \\
\hline \multicolumn{10}{|l|}{ Initial ID } \\
\hline Yes & $1 \cdot 00$ & Ref. & & $1 \cdot 00$ & Ref. & & $1 \cdot 00$ & Ref. & \\
\hline No & $0 \cdot 28$ & $0.13,0.58$ & 0.001 & 0.49 & $0 \cdot 22,1 \cdot 10$ & 0.083 & $7 \cdot 34$ & $0.97,55.6$ & 0.054 \\
\hline \multicolumn{10}{|l|}{ Fe supplementation } \\
\hline No & 1.00 & Ref. & & $1 \cdot 00$ & Ref. & & $1 \cdot 00$ & Ref. & \\
\hline Yes & $0 \cdot 39$ & $0 \cdot 22,0.69$ & 0.004 & 0.91 & $0.42,1.96$ & $0 \cdot 810$ & $1 \cdot 42$ & $0.58,3.50$ & 0.442 \\
\hline Age of the mother (years) & 0.98 & $0.92,1.04$ & 0.425 & $1 \cdot 02$ & $0.94,1 \cdot 11$ & 0.610 & 0.95 & $0.87,1.04$ & $0 \cdot 271$ \\
\hline \multicolumn{10}{|l|}{ Parity } \\
\hline Primipara & $1 \cdot 00$ & Ref. & & $1 \cdot 00$ & Ref. & & $1 \cdot 00$ & Ref. & \\
\hline Multipara & $1 \cdot 21$ & $0 \cdot 71,2 \cdot 06$ & 0.484 & $1 \cdot 47$ & $0 \cdot 68,3 \cdot 18$ & 0.330 & 0.60 & $0 \cdot 28,1 \cdot 30$ & $0 \cdot 197$ \\
\hline \multicolumn{10}{|l|}{ Smoker } \\
\hline No & $1 \cdot 00$ & Ref. & & $1 \cdot 00$ & Ref. & & $1 \cdot 00$ & Ref. & \\
\hline Yes & 0.56 & $0.30,1 \cdot 05$ & 0.073 & 0.67 & $0 \cdot 26,1 \cdot 70$ & 0.401 & 1.99 & $0 \cdot 91,4 \cdot 36$ & 0.086 \\
\hline Gestational age (weeks) & 0.79 & $0.66,0.95$ & 0.010 & 0.57 & $0.44,0.74$ & $<0.001$ & $1 \cdot 24$ & $0.95,1.61$ & 0.109 \\
\hline
\end{tabular}

ID, iron depletion; IDA, iron-deficiency anaemia; Ref., reference category; SF, serum ferritin.

ID was defined as SF $<12 \mu \mathrm{g} / \mathrm{l}$; IDA was defined as anaemia $(\mathrm{Hb}<110 \mathrm{~g} / \mathrm{l})$ and ID simultaneously; risk of haemoconcentration was defined as $\mathrm{Hb}>130 \mathrm{~g} / \mathrm{l}$.

delivery increased with no ID in the first trimester and/or Fe supplementation in the non-adjusted model. Once the model was adjusted, this effect remained the same only for no ID at early gestation.

\section{Discussion}

The present study described a high prevalence of ID and IDA in late pregnancy, adding to the few data that exist on healthy women from the developed countries in southern Europe. The prevalence was higher when women started pregnancy with their Fe levels already depleted and/or they did not take Fe supplements during gestation. The prevalence of risk of haemoconcentration at delivery was also high but Fe supplementation did not seem to enhance it.

All women in the study were volunteers and therefore are not necessarily representative of our whole population, but all of them were healthy (no obstetric pathology), Caucasian and had similar socio-economic status and smoking habits to the rest of our society and to other industrialized countries ${ }^{(16-19)}$. The average infant birth weight and the percentage of babies born preterm or with low birth weight were also similar to those found in other industrialized countries ${ }^{(16,17)}$.

$\mathrm{SF}$ is considered to be the best biochemical parameter for monitoring a deficient Fe status in pregnancy in the absence of infection or inflammation because it correctly identifies the women without Fe stores ${ }^{(20)}$. However, a known limitation of SF is that it also increases with acute or chronic inflammation, malignancy or liver disease ${ }^{(21)}$. As TS does not increase in the presence of inflammation ${ }^{(21)}$, we used both parameters in order to detect inconsistent values (high SF and low TS) that may hide a possible inflammation with Fe deficiency, as suggested by some authors ${ }^{(22,23)}$.

Our results describe the unfavourable evolution of ID, IDA and risk of haemoconcentration during pregnancy.

\section{Frequency of iron depletion (serum ferritin $<12 \mu \mathrm{g} / \boldsymbol{l})$}

The percentage of pregnant women who began gestation with ID $(16 \cdot 2 \%)$ was similar to that found in non-pregnant women in European countries ${ }^{(2,24)}$ and to the great majority of studies conducted in pregnant women of industrialized countries, including at the end of pregnancy when that prevalence is higher ${ }^{(20,25,26)}$, confirming the negative trend in $\mathrm{Fe}$ status of pregnant women in developed countries. Regarding ID at delivery, there was a slight decrease in its prevalence, possibly related to the fact that haemodilution almost disappears at this moment in the pregnancy ${ }^{(27)}$; consequently the real levels of SF in this moment are better shown.

\section{Frequency of iron-deficiency anaemia}

The negative evolution in Fe stores during pregnancy also leads to a negative evolution in the levels of $\mathrm{Hb}$, increasing the prevalence of anaemia. Frequently, the term 'anaemia' has been used as an approximation of IDA ${ }^{(28)}$, which would overestimate its prevalence. Indeed, this relationship between anaemia and IDA can be seen in our 
study, where there are about 30\% more cases of anaemia than of IDA, in agreement with other studies ${ }^{(7,26)}$.

Our results at the end of pregnancy are similar to those published by the WHO in its global database on anaemia $^{(3)}$ and also to the results from other European stu$\operatorname{dies}^{(9,29-31)}$, confirming that Fe deficiency is elevated even in industrialized countries. However, the WHO itself indicates that the data provided include values measured at different moments of gestation, suggesting that estimates in the report ${ }^{(3)}$ are not very accurate, something that we have improved in our study.

\section{Frequency of risk of haemoconcentration}

Haemoconcentration may be caused by an inadequate plasma volume expansion and can be confused with relatively high values of $\mathrm{Hb}$ due to a good $\mathrm{Fe}$ status. Regardless of its cause, a Cochrane meta-analysis used the cut-off value of $\mathrm{Hb}>130 \mathrm{~g} / \mathrm{l}$ to define the risk of haemoconcentration $^{(4)}$; in the present study we decided to use the same cut-off value as we were not able to determine the reason for high $\mathrm{Hb}$ levels.

As far as we are concerned, even if the previous metaanalysis states that the clinical significance of haemoconcentration remains uncertain, some recent studies have found an association of high $\mathrm{Hb}$ levels with poor outcomes such as low birth weight or intra-uterine growth retardation ${ }^{(30,32,33)}$. Recently, our research team also analysed this association and found that haemoconcentration significantly increases the risk of low birth weight (adjusted OR $=11 \cdot 48 ; 95 \%$ CI $1 \cdot 13,116 \cdot 6)^{(33)}$. Therefore, it is important to establish the percentage of pregnant women who may be at risk.

In the present study, we observed that risk of haemoconcentration increased during pregnancy, from $1.9 \%$ to $13 \cdot 3 \%$ at delivery. In the previously mentioned Cochrane meta-analysis, the prevalence of this risk during the second or third trimester of gestation described for developed countries ranges from $8.7 \%$ in Finland to $42 \%$ in Norway ${ }^{(4)}$, but with no data available from southern Europe. Our study can therefore provide some data for this part of Europe. The high prevalence of risk of haemoconcentration found in some of these studies might be due to only selecting women who were not anaemic at the beginning of their pregnancy and who therefore had higher values of $\mathrm{Hb}$ than in our study.

\section{Importance of initial iron stores and of iron supplementation}

As in other studies, we observed that the prevalence of ID and IDA was more common when women begin pregnancy with ID and when they are non-supplemented, and in this situation the risk of haemoconcentration was lower ${ }^{(4,8,34)}$

In order to further study the differences observed in the prevalence caused by these two risk factors (initial Fe stores and Fe supplementation), we assessed the probability of having ID, IDA and $\mathrm{Hb}>130 \mathrm{~g} / \mathrm{l}$ at delivery using multiple logistic regression analyses that allowed the separation of the effects of each risk factor, each taking into account the other, and also some other variables that may be associated with the studied relationship ${ }^{(35)}$.

Regarding the prevention of ID and IDA, we observed that initially good Fe stores protected against ID and IDA at delivery, although in the case of IDA, we only observed a protective trend that was not statistically significant. This suggests the importance of starting pregnancy with good Fe stores in order to cover any increased Fe needs and to avoid Fe deficiency, reaffirming the findings of Milman et al. in a study conducted on 301 healthy, pregnant Danish women ${ }^{(8)}$.

We also found that Fe supplementation $(57 \cdot 8 \mathrm{mg} / \mathrm{d}$ on average) exerted a protective effect against ID at delivery, but did not have a clear, observable effect on IDA. Similar results were obtained in a previous study conducted by Ekstrom et al., who reported that a total dose of $2400 \mathrm{mg}$ Fe consumed $(30 \mathrm{mg} / \mathrm{d})$ had no additional benefit in increasing $\mathrm{Hb}$ levels when the supplementation started late and lasted around 12 weeks ${ }^{(10)}$. We observed the same lack of effect even when supplementing with higher total doses of Fe of about $8367 \mathrm{mg}(57 \cdot 8 \mathrm{mg} / \mathrm{d})$ and for a longer period (about 22 weeks). High doses of Fe supplementation protect against Fe deficiency states in a great proportion of women, but it has been associated with oxidative stress and haemoconcentration ${ }^{(4,30,31)}$. Consequently, recent recommendations suggest using doses of Fe lower than $60 \mathrm{mg} / \mathrm{d}^{(4,36)}$. These low or moderate $\mathrm{Fe}$ doses taken during this limited number of weeks might be enough to improve Fe stores, but should be taken for a longer period of time to increase significantly the $\mathrm{Hb}$ levels at the end of pregnancy. In this situation, we emphasize the need for individualizing Fe prescriptions, although more randomized clinical trials are required.

Concerning the risk of haemoconcentration, it appeared to be related to no initial ID, but we did not observe any association with the moderate Fe supplementation taken in the present study, once adjusted for no initial ID and for some other variables related with the studied relationship.

Currently, there is no clear relationship between Fe supplementation and the risk of haemoconcentration at the end of pregnancy. While on the one hand, the Cochrane meta-analysis indicates that the risk of haemoconcentration is more common among women who receive daily $\mathrm{Fe}$ supplements than among those who receive no treatment or take placebo ${ }^{(4)}$, some studies do not observe this relationship and suggest that, in healthy pregnant women, Fe supplementation cannot increase Hb levels beyond what is optimal for a given person ${ }^{(6,10)}$. However, none of these studies took into account the initial Fe levels of pregnant women as suggested by Milman et al. In their study they assessed the effectiveness of different Fe supplementation doses (20, 40, 60, $80 \mathrm{mg} / \mathrm{d}$ ) according to the initial Fe stores, suggesting that women 
having $\mathrm{SF} \leq 30 \mu \mathrm{g} / \mathrm{l}$ at early pregnancy, as in our study, should take $80-100 \mathrm{mg}$ ferrous $\mathrm{Fe} / \mathrm{d}$, while women with higher initial Fe stores could take less Fe supplementation and still prevent Fe deficiency states ${ }^{(8)}$. Therefore, women with high Fe levels at early pregnancy may be at increased risk of haemoconcentration if they receive a higher Fe supplementation dose.

There might be other risk factors that favour haemoconcentration in pregnant women. In our opinion, the genetic alterations in the gene $H F E$, which increases the absorption of dietary $\mathrm{Fe}^{(37)}$, could be associated with higher initial $\mathrm{Hb}$ levels ${ }^{(38)}$. Therefore, we believe that daily Fe supplementation, which is routinely recommended in pregnancy, may be unnecessary for women with this genetic alteration.

However, it is not clearly known what implications other factors can have, such as initial Fe stores and the genetic alterations of women, in the assessment of the effect of $\mathrm{Fe}$ supplementation in anaemic and nonanaemic pregnant women. Therefore, it is unlikely that the same Fe supplementation pattern is optimal for all pregnant women because each one could have different characteristics regarding their genetic and initial Fe levels.

\section{Conclusion}

In the present study we observed that $45 \cdot 7 \%$ of pregnant women reached delivery with ID, $13.5 \%$ with IDA and a $13 \cdot 3 \%$ at risk of haemoconcentration. The prevalence of ID and IDA almost doubled and the prevalence of risk of haemoconcentration decreased among women who started pregnancy with ID and among those who did not take Fe supplements.

Therefore, starting pregnancy with no ID and/or taking moderate Fe supplementation decreases the likelihood of ID at the end of pregnancy, although it does not appear to be enough to prevent IDA in a large percentage of women. It is unclear whether the effects of Fe supplementation enhance haemoconcentration.

Further studies are necessary to determine the most appropriate nutritional advice that can be tailored to the needs of pregnant women according to their individual characteristics.

\section{Acknowledgements}

Sources of funding: This study was financially supported by a grant (PI052462) from the Health Research Fund of the Ministry of Health and Consumption (Madrid, Spain) (Instituto de Salud Carlos III, Fondo de Investigación Sanitaria, Ministerio de Sanidad y Consumo). Conflict of interest: None of the authors have any financial or other potential conflicts of interests concerning this paper. Authors' contributions: V.A. designed and conducted the study, contributed to the analyses and interpretation of the data, and drafted the manuscript. B.R. and N.A. assisted in the fieldwork, the analyses and interpretation of the data, and writing of the manuscript. Acknowledgements: The authors would like to thank all of the participating pregnant women for their enthusiastic collaboration. They also thank the Clinical Chemistry Laboratories of the Hospital Sant Joan de Reus (Catalunya, Spain) for help with the blood analyses, Ms Pilar Hernández for her assessment in the statistical analyses and Mr Phil Hoddy for editing the English text.

\section{References}

1. Bothwell TH (2000) Iron requirements in pregnancy and strategies to meet them. Am J Clin Nutr 72, 1 Suppl., 257S-264S.

2. Hallberg L (1995) Results of surveys to assess iron status in Europe. Nutr Rev 53, 314-322.

3. World Health Organization (2008) Worldwide Prevalence of Anaemia 1993-2005. WHO Global Database on Anaemia. Geneva: WHO.

4. Pena-Rosas JP \& Viteri FE (2009) Effects and safety of preventive oral iron or iron+folic supplementation for women during pregnancy. Cochrane Database Syst Rev issue 4, CD004736.

5. Hernández-Martínez C, Canals J, Aranda N et al. (2011) Effects of iron deficiency on neonatal behavior at different stages of pregnancy. Early Hum Dev 87, 165-169.

6. Scanlon KS, Yip R, Schieve LA et al. (2000) High and low hemoglobin levels during pregnancy: differential risks for preterm birth and small for gestational age. Obstet Gynecol 96, 741-748.

7. Siega-Riz AM, Hartzema AG, Turnbull C et al. (2006) The effects of prophylactic iron given in prenatal supplements on iron status and birth outcomes: a randomized controlled trial. Am I Obstet Gynecol 194, 512-519.

8. Milman N, Byg KE, Bergholt T et al. (2006) Body iron and individual iron prophylaxis in pregnancy - should the iron dose be adjusted according to serum ferritin? Ann Hematol 85, 567-573.

9. Aranda N, Ribot B, Garcia E et al. (2011) Pre-pregnancy iron reserves, iron supplementation during pregnancy, and birth weight. Early Hum Dev 87, 791-797.

10. Ekström EC, Hyder SM, Chowdhury AM et al. (2002) Efficacy and trial effectiveness of weekly and daily iron supplementation among pregnant women in rural Bangladesh: disentangling the issues. Am J Clin Nutr 76, 1392-1400.

11. Chen X, Scholl TO \& Stein TP (2006) Association of elevated serum ferritin levels and the risk of gestational diabetes mellitus in pregnant women: The Camden study. Diabetes Care 29, 1077-1082.

12. Hollingshead AB (2011) Four factor index of social status. Yale J Sociol 8, 21-52; available at http://www.yale.edu/ sociology/yjs/yjs_fall_2011.pdf

13. Gomez F, Simo JM, Camps J et al. (2000) Evaluation of a particle-enhanced turbidimetric immunoassay for the measurement of ferritin: application to patients participating in an autologous blood transfusion program. Clin Biochem 33, 191-196.

14. Fairbanks VF \& Klee GG (1999) Biochemical aspects of haematology. In Tietz Textbook of Clinical Chemistry, pp. 1698-1705 [CA Burtis and ER Ashwood, editors]. Philadelphia, PA: WB Saunders.

15. Centers for Disease Ccontrol and Prevention (1998) Recommendations to prevent and control iron deficiency in the United States. MMWR Recomm Rep 47, 1-29.

16. Río I, Castelló A, Jané M et al. (2010) Reproductive and perinatal health indicators in immigrant and Spanish-born 
women in Catalonia and Valencia (2005-2006). Gac Sanit 24, 123-127.

17. Carrillo SM, Pérez Guillén A, Hernández Hernández RA et al. (2010) Anthropometric nutritional evaluation of pregnant women and its relation with the product of the gestation. Nutr Hosp 25, 832-837.

18. Pueyo V, Güerri N, Oros D et al. (2011) Effects of smoking during pregnancy on the optic nerve neurodevelopment. Early Hum Dev 87, 331-334.

19. Reinold C, Dalenius K, Brindley P et al. (2011) Pregnancy Nutrition Surveillance 2009 Report. Atlanta GA: US Department of Health and Human Services, Centers for Disease Control and Prevention.

20. Walsh T, O'Broin SD, Cooley S et al. (2011) Laboratory assessment of iron status in pregnancy. Clin Chem Lab Med 49, 1225-1230.

21. Zimmermann MB (2008) Methods to assess iron and iodine status. Br J Nutr 99, Suppl. 3, S2-S9.

22. Muñoz M, García-Erce JA \& Remacha ÁF (2011) Disorders of iron metabolism. Part II: iron deficiency and iron overload. J Clin Pathol 64, 287-296.

23. Rambod M, Kovesdy CP \& Kalantar-Zadeh K (2008) Combined high serum ferritin and low iron saturation in hemodialysis patients: the role of inflammation. Clin J Am Soc Nephrol 3, 1691-1701.

24. Bermejo B, Olona M, Serra M et al. (1996) Prevalence of iron deficiency in the female working population in the reproductive age. Rev Clin Esp 196, 446-450.

25. Duffy EM, Bonham MP, Wallace JM et al. (2010) Iron status in pregnant women in the Republic of Seychelles. Public Health Nutr 13, 331-337.

26. Cogswell ME, Parvanta I, Ickes L et al. (2003) Iron supplementation during pregnancy, anemia and birth weight: a randomized controlled trial. Am J Clin Nutr 78, 773-781.

27. Milman N (2011) Postpartum anemia I: definition, prevalence, causes, and consequences. Ann Hematol 90, 1247-1253.
28. Morón C \& Viteri FE (2009) Update on common indicators of nutritional status: food access, food consumption, and biochemical measures of iron and anemia. Nutr Rev 67, Suppl. 1, S31-S35.

29. Milman N (2008) Prepartum anaemia: prevention and treatment. Ann Hematol 87, 949-959.

30. Scholl TO (2005) Iron status during pregnancy: setting the stage for mother and infant. Am J Clin Nutr 81, issue 5, 1218S-1222S.

31. Scholl TO (2011) Maternal iron status: relation to fetal growth, length of gestation, and iron endowment of the neonate. Nutr Rev 69, Suppl. 1, S23-S29.

32. Von Tempelhoff GF, Heilmann L, Rudig L et al. (2008) Mean maternal second-trimester hemoglobin concentration and outcome of pregnancy: a population-based study. Clin Appl Thromb Hemost 14, 19-28.

33. Aranda N, Ribot B, Viteri F et al. (2012) Predictors of haemoconcentration at delivery: association with low birth weight. Eur J Nutr (Epublication ahead of print version).

34. Milman N, Bergholt T, Eriksen L et al. (2005) Iron prophylaxis during pregnancy - how much iron is needed? A randomized dose-response study of $20-80 \mathrm{mg}$ ferrous iron daily in pregnant women. Acta Obstet Gynecol Scand 84, 238-247.

35. Barroso F, Allard S, Kahan BC et al. (2011) Prevalence of maternal anaemia and its predictors: a multi-centre study. Eur J Obstet Gynecol Reprod Biol 159, 99-105.

36. Institute of Medicine (2001) Iron. In Dietary Reference Intakes for Vitamin A, Vitamin K, Arsenic, Boron, Chromium, Copper, Iodine, Iron, Manganese, Molybdenum, Nickel, Silicon, Vanadium, and Zinc, pp. 290-393. Washington, DC: National Academy Press.

37. Bacon BR (2012) Hemochromatosis: discovery of the HFE gene. Mo Med 109, 133-136.

38. Mast AE, Lee TH, Schlumpf KS et al. (2012) The impact of HFE mutations on haemoglobin and iron status in individuals experiencing repeated iron loss through blood donation. Br J Haematol 156, 388-401. 